\title{
Atos de Ler a Educação Especial na Educação Infantil: reordenações políticas e os serviços educacionais especializados
}

\author{
Fabiane Romano de Souza Bridi' \\ Melina Chassot Benincasa Meirelles" \\ 'Universidade Federal de Santa Maria (UFSM), Santa Maria/RS - Brasil \\ "Universidade Federal do Rio Grande do Sul (UFRGS), Porto Alegre/RS-Brasil
}

RESUMO - Atos de Ler a Educação Especial na Educação Infantil: reordenações políticas e os serviços educacionais especializados. O presente artigo objetiva produzir uma leitura sobre a oferta dos serviços de Educação Especial na Educação Infantil e seus modos de organização no contexto da Rede Municipal de Ensino de Santa Maria (RME/SM). Como questões norteadoras, indagamos de que forma as reordenações políticas no campo educacional incidem sobre a oferta da Educação Especial na Educação Infantil? Como a leitura de um contexto específico, no caso a RME/SM, sinaliza tais mudanças na oferta da Educação Especial na Educação Infantil? Para fins de análise, foram utilizadas informações do Censo da Educação Básica. Como possíveis leituras, destacamos a necessidade de ampliação das matrículas dos alunos da Educação Especial na Educação Infantil e a oferta dos serviços especializados a essas crianças; um olhar atento para os processos de identificação e diagnóstico e para as ações de preenchimento do Censo Escolar.

Palavras-chave: Educação Infantil. Educação Especial. Inclusão Escolar. Censo da Educação Básica.

ABSTRACT - Acts of Reading Early Childhood Special Education: political realignment and specialized educational services. This article aims to produce a reading about the offer of Special Education in Early Childhood Education and its modes of organization in the context of the Municipal School Network of Santa Maria (RME/SM). As the guiding questions, we asked how does political realignment in the educational field focus on the provision of Special Education in Early Childhood Education? How does the reading of a specific context, as RME/SM, indicate such changes in the provisions of Special Education in Early Childhood Education? For analysis purposes, information from the Basic Education Census was used. As possible readings, we highlight the need to increase the enrollment of Special Education students in Early Childhood Education and the provision of specialized services to these children, as well as to have a closer look at the processes of identification and diagnosis and at the filling the School Census. Keywords: Early Childhood Education. Special Education. School Inclusion. Basic Education Census.

Educação \& Realidade, Porto Alegre, v. 39, n. 3, p. 745-769, jul./set. 2014.

Disponível em: <http://www.ufrgs.br/edu_realidade> 
Atos de Ler a Educação Especial na Educação Infantil

\title{
Para Iniciar a Leitura
}

\begin{abstract}
Nunca aconteceu, ao ler um livro, interromper com frequência a leitura, não por desinteresse, mas, ao contrário, por afluxo de ideias, excitações, associações? Numa palavra, nunca lhe aconteceu ler levantando a cabeça? essa leitura, ao mesmo tempo irrespeitosa, pois que corta o texto, e apaixonada, pois que a ele volta e dele se nutre, que tentei escrever. Para escrevê-la, para que minha leitura se torne por sua vez objeto de uma nova leitura (a dos leitores $\mathrm{S} / \mathrm{Z}$ ), tive evidentemente de sistematizar todos esses momentos em que a gente 'levanta a cabeça'. Em outras palavras, interrogar a minha própria leitura é tentar captar a forma de todas as leituras (forma: único lugar da ciência), ou ainda: suscitar uma teoria da leitura (Barthes, 2004, p. 26, grifos do autor)
\end{abstract}

$\mathrm{Na}$ aposta da leitura como desejo de escrever, na possibilidade do sujeito de se criar e recriar na produção do texto, ou ainda no exercício de ler "levantando a cabeça"... Como pesquisadoras/leitoras tomamos o gesto de leitura como uma possibilidade de ler, fora das margens, outras ideias, outras significações. Desse modo, convidamos o leitor a ler (adentrar) em um texto que, ao mesmo tempo, constrói uma leitura e produz uma análise sobre essa própria leitura, tomando nosso objetivo como fio condutor

Partindo das relações entre Educação Infantil e Educação Especial, o presente artigo objetiva produzir uma leitura sobre a oferta dos serviços de Educação Especial na Educação Infantil e seus modos de organização no contexto da Rede Municipal de Ensino de Santa Maria (RME/SM). Tomando as recentes mudanças políticas no campo da Educação, que envolvem, por exemplo, a obrigatoriedade do ensino para as crianças de 4-5 anos, questionamos os efeitos que estas produzem na organização dos serviços da Educação Especial. De que forma as reordenações políticas no campo educacional incidem sobre a oferta da Educação Especial na Educação Infantil? Como a leitura de um contexto específico, no caso a RME/SM, sinaliza tais mudanças? Para tanto, produzir uma leitura sobre a oferta dos serviços da Educação Especial nesta etapa de ensino envolve incluir, neste ato de ler, as matrículas dos alunos da Educação Especial na Educação Infantil.

No movimento de ler para compreender, ou para começarmos a compreender algo, "[...] Todos lemos a nós e ao mundo à nossa volta para vislumbrar o que somos e onde estamos. Lemos para compreender, ou para começar a compreender. Não podemos deixar de ler. Ler, quase como respirar, é nossa função essencial" (Manguel, 1997, p. 19-20, grifo nosso). No processo de construção escrita, tomamos a literatura como uma possível parceira nesta tarefa. Consideramos um campo potente na relação com o olhar para um contexto, no desafio de analisar dados numéricos, muitas vezes, duros do campo estatístico-educacional. 
$\mathrm{O}$ presente texto se configura em três movimentos de leitura. $\mathrm{O}$ primeiro deles envolve o ato de ler a Educação Infantil a partir de suas determinações legais, da oferta de seus serviços, da matrícula dos alunos, da formação dos profissionais que atuam nesta etapa de ensino. $\mathrm{O}$ segundo movimento de leitura envolve problematizar as relações existentes entre esses dois campos do conhecimento, principalmente no que tange a organização dos serviços da Educação Especial. O terceiro gesto intenciona olhar para essas relações a partir da leitura de um contexto específico, no caso a Rede Municipal de Ensino de Santa Maria. Para tanto, analisamos dados da referida rede no que diz respeito à: estrutura e organização educacional; Educação Infantil no universo na rede; matrículas de alunos da Educação Especial e oferta do atendimento educacional especializado para essas crianças; e aos processos de identificação e diagnósticos desses alunos a partir dos dados do Censo da Educação Básica.

\title{
No Ato de Ler a Educação Infantil de um Determinado Lugar...
}

Mapear os serviços especializados oferecidos aos alunos da educação especial $^{1}$, de zero a cinco anos de idade ${ }^{2}$, tem sido um grande desafio. Conhecer um determinado serviço para a infância nos faz pensar na própria oferta da educação infantil, a qual parece ainda não contemplar todas as crianças.

\begin{abstract}
Embora o Instituto Brasileiro de Geografia e Estatística (IBGE) não tenha divulgado dados mais específicos do Censo 2010, pelas informações disponíveis pode-se estimar a população de 0 a 5 anos em aproximadamente 16 milhões. Se em 2009 a população desta faixa etária atendida pela educação infantil era de cerca de 6,8 milhões, verifica-se que apenas $42,5 \%$ tiveram acesso a essa etapa de ensino, muito abaixo da previsão (Bueno; Meletti, 2011, p. 280).
\end{abstract}

Os autores acima sinalizam a posição ainda periférica da educação infantil no que se refere ao acesso à educação. É possível compreendermos alguns desses movimentos por meio dos documentos legais e normativos que lançam as diretrizes para a oferta dos serviços e configuram esta etapa educacional, como também dos dados do Censo da Educação Básica considerados “[...] dados estatístico-educacionais de âmbito nacional, coordenados pelo Instituto Nacional de Estudos e Pesquisas Educacionais Anísio Teixeira (INEP) [...] Trata-se do principal instrumento de coleta de informações sobre a educação básica” (Meletti; Bueno, 2013, p. 77). Vale ainda ressaltar que tais informações possibilitam a avaliação e efetividade das políticas públicas.

A partir da Lei de Diretrizes e Bases da Educação - LDB 9.394/96, vivenciamos o processo de municipalização do ensino, por meio da definição de responsabilidades da esfera municipal no que se refere à educa- 
ção: os municípios passaram a ser responsáveis pela oferta da educação infantil e prioritariamente do ensino fundamental. Segundo a referida Lei, a oferta da Educação Infantil deve ser realizada por meio de "I - creches, ou entidades equivalentes, para crianças de até três anos de idade; II - pré-escolas, para crianças de quatro a seis anos de idade" (Brasil, 1996, online). Apesar de estar prevista a oferta da Educação Infantil no âmbito legal, a responsabilidade prioritária dos municípios com o Ensino Fundamental faz com que se justifique a inexistência de ações que garantam o acesso e a permanência na escola das crianças pequenas.

Campos et al. (2011) apontam duas importantes mudanças do ponto de vista legal, ao falarmos sobre a Educação Infantil. O primeiro, já sinalizado, faz referência "a incorporação das creches ao setor educacional”, no momento em que a Educação Infantil passa a ser definida como a primeira etapa da educação básica. O segundo ponto, diz respeito à criação do Fundo de Manutenção e Desenvolvimento da Educação Básica e de Valorização do Magistério - FUNDEB, o qual vem substituir o Fundo de Manutenção e Desenvolvimento do Ensino Fundamental e de Valorização do Magistério - FUNDEF. Desse modo, “[...] a creche e a pré-escola passaram pela primeira vez a ter seu financiamento previsto em lei, ao lado das demais etapas da educação básica” (2011, p. 22). Nessa direção, de acordo com Campos, Füllgraf e Wiggers (2006, p. 90), teríamos um terceiro aspecto importante a destacar, relacionado à "[...] exigência de formação prévia para professores e educadores de crianças pequenas, preferencialmente em nível superior, mas admitindo o curso de magistério em nível médio”. Ponto abordado na própria LDB/96, em seu Art. $62^{\circ}$ :

\begin{abstract}
A formação de docentes para atuar na educação básica far-se-á em nível superior, em curso de licenciatura, de graduação plena, em universidades e institutos superiores de educação, admitida, como formação mínima para o exercício do magistério na educação infantil e nas quatro primeiras séries do ensino fundamental, a oferecida em nível médio, na modalidade Normal (Brasil, 1996, online, grifo nosso).
\end{abstract}

Embora saibamos que essa exigência ainda não tenha sido contemplada em sua totalidade, o Censo da Educação Básica (Brasil/INEP, 2013a) nos apresenta, na etapa da Educação Infantil, um contingente de $36,4 \%$ de professores ainda sem formação superior e de $63,6 \%$ com formação superior. No que se refere ao Ensino Fundamental (anos iniciais) ${ }^{3}, 75 \%$ dos docentes tem formação superior, e $25 \%$ não tem; já nos anos finais do Ensino Fundamental, 90,4\% dos docentes tem formação no ensino superior, e 9,6\% não, dados que “[...] mostram que o nível de formação melhora quanto mais elevada é a etapa de atuação do professor na educação básica” (Brasil/INEP, 2013a, p. 38). Assim, reconhecemos que é realidade nas escolas a contratação de profissionais sem formação no magistério, que atuam a partir de diferentes designações, tais como trocar e alimentar as crianças pequenas. Esses, com muita 
frequência, são os únicos responsáveis pela criança, ocupando-se também pela dimensão pedagógica e educativa, colocando em xeque os princípios fundamentais e indissociáveis da Educação Infantil - o cuidar e o educar.

Nessa direção, ações e programas têm sido ofertados pelo Ministério da Educação e Cultura (MEC), por meio do Plano de Desenvolvimento da Educação (PDE). Podemos citar como exemplo a Rede Nacional de Formação Continuada de Professores, criada em 2004, na modalidade de ensino a distância, em parceria com a Universidade Aberta do Brasil (UAB). Por meio desta Rede, são ofertados cursos de formação continuada aos professores de educação básica dos sistemas públicos de ensino, com o objetivo de contribuir para a melhoria da formação e da prática pedagógica. De acordo com o MEC (Brasil, 2014), a referida formação tem como objetivo:

[...] contribuir para a melhoria da formação dos professores e alunos. [...] Em parcerias com as instituições de ensino superior públicas que integram a Rede são produzidos materiais de orientação para cursos à distância e semipresenciais, com carga horária de 120 horas. [...] As áreas prioritárias de formação são: alfabetização e linguagem, educação matemática e científica, ensino de ciências humanas e sociais, artes e educação física (Brasil, 2014, online).

Temos ainda o Plano Nacional de Formação de Professores da Educação Básica (PARFOR), programa emergencial “[...] implantado em regime de colaboração entre a Capes, os estados, municípios, o Distrito Federal e as Instituições de Educação Superior - IES”, destinado aos professores da rede pública de educação básica sem formação superior adequada à sua área de atuação. O Programa visa a oferta de turmas especiais em cursos de Licenciatura, Segunda Licenciatura e Formação Pedagógica ${ }^{4}$. Cabe destacar que essas ações visam atender a uma prerrogativa legal de formação exigida pela Lei de Diretrizes e Bases da Educação Nacional LDB 9.394/965.

Na continuidade, após destacar a configuração legal que a etapa da Educação Infantil ganha, remetemo-nos a pensar o acesso, por parte das crianças pequenas, à escola. No que tange às matrículas dos alunos da Educação Infantil, conforme os dados do Censo da Educação Básica (Brasil/INEP, 2013a), temos a ampliação da oferta da Educação Infantil, em especial na creche, a qual apresentou um crescimento de 10,5\% nas matrículas. Já, na pré-escola, houve um aumento de 1,6\%, “[...] o que representa mais de $80 \%$ da coorte de 4 a 5 anos de idade" (Brasil/INEP, 2013a, p. 18). Vale destacar que, devido à reorganização da pré-escola, com a implantação do ensino fundamental de nove anos, parte das crianças com seis anos, antes atendidas na Educação Infantil, passam a ser matriculadas no Ensino Fundamental, o que pode, de acordo com o Censo, apresentar certa estabilidade da matrícula na pré-escola. Ainda de acordo com os dados estatístico-educacionais verifica-se que, 
Atos de Ler a Educação Especial na Educação Infantil

[...] a maior parte das matrículas da creche está sob a responsabilidade das redes municipais de ensino, que abrangem $63,1 \%$ do total, [...] e a pré-escola segue a mesma tendência. Os municípios detêm $74,2 \%$ do atendimento, [...]. A rede privada participa com $24,7 \%$, seguida das redes estaduais, com $1,1 \%$, e da rede federal, que não tem uma participação significativa sobre o total de matrículas dessa etapa (Brasil/INEP, 2013a, p. 18).

Embora os dados apresentem uma maior oferta da Educação Infantil no setor público e um aumento progressivo no acesso à escola por parte das crianças pequenas, não necessariamente essa expansão vem acompanhada por padrões de qualidade no que compete à organização do trabalho pedagógico. O que é reafirmado por Cruz (2006, p. 13), ao pontuar que "[...] há uma tensão entre o que foi duramente conquistado no plano legal e interesses e concepções restritivas quanto à melhoria da qualidade da Educação Infantil que procuram incentivar serviços de baixo custo".

Até o presente momento, apresentamos elementos que nos auxiliam a produzir uma leitura da Educação Infantil, tomando a leitura como uma operação descontínua e fragmentária.

Subverte, dessa forma, a força da informação e da transmissão, ao afirmar que ler é um ato de invenção. É a construção de um sentido e não sua localização ou desvelamento. Avisa, contudo, há limites. Trata-se da impossibilidade de tudo ler e construir porque o texto é sempre inacabado: um espaço potencial que se faz pela vivência do leitor, mas que paradoxalmente não se encerra nessa significação. É somente porque está inacabado que se abre espaço para o trabalho do leitor. Sua autoridade, porém, é limitada (Vasques, 2008, p. 154, grifo nosso).

Desse modo, na possibilidade de ler e reler sempre, na busca de uma construção de sentidos, a partir de diferentes fontes, recorremos a pontos da legislação que oferecem à Educação Infantil outro lugar no cenário educacional brasileiro; dados censitários que compreendem desde as matrículas do acesso à educação até a formação (ainda em processo de constituição) dos profissionais responsáveis por essa etapa de ensino. Reconhecemos que, para além das possibilidades de acesso, as condições de organização do trabalho pedagógico exercem papel decisivo nessa conjuntura.

Esse primeiro movimento de leitura objetivou o conhecimento de elementos da Educação Infantil considerando sua história e especificidade, seus contornos e características. Objetivou situar o leitor na demarcação de um campo, intentando contextualizar os fenômenos, as histórias singulares para que neste cenário se possa pensar nos alunos da Educação Especial matriculados nesta etapa de ensino. 


\title{
Em um Segundo Movimento de Leitura: uma história entre educação infantil e educação especial
}

No que se refere aos alunos da educação especial na educação infantil, observamos a pouca existência de materiais didáticos e formativos publicados pelo MEC/SECADI com a intencionalidade de subsidiar a prática pedagógica. Nessa direção, identificamos na Coleção Saberes e Práticas de Inclusão (Brasil, MEC/SEESP ${ }^{6}, 2006$, p. 3) o único material de apoio que aborda "[...] temas específicos sobre o atendimento educacional de crianças com necessidades educacionais especiais, do nascimento aos seis anos de idade". A coletânea aborda o desenvolvimento da prática pedagógica com enfoque nas Dificuldades Acentuadas de Aprendizagem; Deficiência Múltipla; Deficiência Física; Surdocegueira; Surdez; Deficiência Visual e Altas Habilidades/Superdotação?

Segundo Benincasa (2011), historicamente o que tem sido oferecido, conforme o material referendado acima, são os serviços de apoio pedagógico especializado, como os serviços itinerantes ${ }^{8}$ e o programa de intervenção precoce ${ }^{9}$. Serviços que vêm sendo ofertados pelos setores associados à saúde e pelas instituições especializadas públicas (eventuais escolas estaduais ou municipais especiais) e/ou filantrópicas de caráter assistencialista, como a Associação de Pais e Amigos dos Excepcionais (APAE).

Do ponto de vista legal, destacamos a Resolução n. 2/2001, a qual Institui as Diretrizes Nacionais para a Educação Especial na Educação Básica, e a Política Nacional de Educação Especial na Perspectiva da Educação Inclusiva (2008), como dois documentos que sinalizam a importância de um atendimento desde a educação infantil. $\mathrm{O}$ primeiro destaca no Parágrafo único do Art.1:

\begin{abstract}
O atendimento escolar desses alunos terá início na educação infantil, nas creches e pré-escolas, assegurando-lhes os serviços de educação especial sempre que se evidencie, mediante avaliação e interação com a família e a comunidade, a necessidade de atendimento educacional especializado (Brasil, 2001, p. 1).
\end{abstract}

No texto da atual Política Nacional de Educação Especial (2008), percebemos, de modo mais enfático, essa importância no momento em que a educação infantil é inferida como um tempo no qual se “[...] desenvolvem as bases necessárias para a construção do conhecimento e desenvolvimento global do aluno".

O acesso à educação tem início na educação infantil, $n a$ qual se desenvolvem as bases necessárias para a construção do conhecimento e desenvolvimento global do aluno. Nessa etapa, o lúdico, o acesso às formas diferenciadas de comunicação, a riqueza de estímulos nos aspectos físicos, emocionais, cognitivos, psicomotores e sociais e a convivência

Educação \& Realidade, Porto Alegre, v. 39, n. 3, p. 745-769, jul./set. 2014.

Disponível em: <http://www.ufrgs.br/edu_realidade> 
Atos de Ler a Educação Especial na Educação Infantil

com as diferenças favorecem as relações interpessoais, o respeito e a valorização da criança (Brasil, 2008, p. 16).

No entanto, temos a oferta do atendimento educacional especializado para as crianças de zero a três anos realizado com a intervenção precoce: “[...] do nascimento aos três anos, o atendimento educacional especializado se expressa por meio de serviços de intervenção precoce que objetivam otimizar o processo de desenvolvimento e aprendizagem em interface com os serviços de saúde e assistência social" (Brasil, 2008, p. 16). Porém, não encontramos maiores detalhamentos sobre os pressupostos, o enfoque e a organização que deva caracterizar a oferta desse serviço. Além disso, a referência às demais crianças de quatro e cinco anos também aparece de forma genérica. Afirma-se o acesso à educação ainda na Educação Infantil sem trazer elementos que refiram o atendimento educacional especializado na pré-escola.

Atualmente, com o Programa de Implantação das Salas de Recursos Multifuncional (MEC/SECADI), as escolas recebem mobiliário, equipamentos e materiais didáticos, pedagógicos e de acessibilidade. Cabe ressaltar que o envio do material é voltado para o trabalho com os alunos do Ensino Fundamental. Sobre isso, Garcia e Lopez (2011, p. 1) apontam para um modelo de Educação Especial,

\begin{abstract}
[...] que na perspectiva inclusiva assume um papel de complementaridade à Educação Básica. Contudo, tal relação toma como referência para toda a Educação Básica o trabalho desenvolvido no Ensino Fundamental regular. Uma consequência importante aí colocada é que o trabalho pedagógico desenvolvido na Educação Infantil e suas especificidades não tem sido considerado nas discussões que tem sustentado a política de Educação Especial, a qual sustenta um modelo de atendimento educacional especializado padrão para toda a Educação Básica, desconsiderando as condições institucionais, a faixa etária dos educandos, entre outros fatores (grifo nosso).
\end{abstract}

Dessa forma, podemos inferir que o espaço ainda periférico ocupado pela Educação Infantil no cenário da Educação Básica se reflete ao adentrarmos na especificidade do campo da Educação Especial. Nesta relação - Educação Infantil e Educação Especial - ainda não contamos com uma organização e um investimento específicos. Referimo-nos à proposição de possibilidades de atendimento capazes de contemplar a especificidade desse período do desenvolvimento infantil e dessa etapa de escolarização. Reconhecemos o desafio de adentrar em um campo, como o da educação infantil, ainda frágil no que tange ao acesso a um ensino de qualidade para todas as crianças. Reconhecemos também que essa fragilidade se acentua ao pensarmos os processos de inclusão e a oferta de serviços especializados que contemplem essa etapa de ensino. 
Na primeira década da implantação da LDBEN, dados oficiais (Brasil, 2008) indicam um crescimento significativo de matrículas de sujeitos com deficiência, transtornos globais do desenvolvimento e superdotação/altas habilidades nas escolas regulares, mas, no que se refere à Educação Infantil, o quadro não acompanha essa tendência: do total de matrículas na educação básica em 2006, apenas 16\% ocorreram na Educação Infantil e a grande maioria está concentrada nas escolas e classes especiais (24.005 crianças matriculadas em turmas comuns para 89.083 em escolas e classes especiais) (Oliveira; Padilha, 2013, p. 201).

Os dados censitários expressos acima anunciam a vasta caminhada que a Educação Especial e a Educação Infantil têm pela frente ao pensarmos nos alunos da Educação Especial nessa etapa de ensino. É consenso nas duas áreas a importância dos primeiros anos de vida para os processos de aprendizagem e desenvolvimento infantil. Essa dimensão acentua-se ao pensarmos nas especificidades dos alunos da Educação Especial. Apesar desse reconhecimento, a proposição de serviços e ações voltadas a esses sujeitos não se constitui como movimento prioritário. Nesse sentido, perguntamo-nos como seriam os dados se houvesse um maior investimento do atendimento educacional especializado no espaço das instituições públicas infantis?

Nessa direção, demarcamos a importância do investimento em ações investigativas que se ocupem da educação infantil e também fortaleçam e estreitem os laços entre Educação Especial e Educação Infantil, o que se constitui como ponto "[...] de necessário investimento pela escassez de serviços e pela importância dos apoios em momento inicial da vida e da escolarização das crianças com deficiência" (Baptista, 2011, p. 68).

De acordo com os últimos dados do painel de controle do MEC (Brasil, 2013c), foram implantadas, no período de 2005 a 2013, 39.301 Salas de Recursos Multifuncional em 5046 municípios brasileiros ${ }^{10}$. Deste universo, muitas escolas de Educação Infantil foram contempladas em muitos municípios, possibilitando aos alunos da educação especial um espaço de atendimento especializado. Movimentos interessantes que parecem apontar para um ainda tímido deslocamento quanto à oferta de atendimento aos pequenos - anteriormente a cargo quase que exclusivamente das instituições especializadas filantrópicas de caráter assistencialista, que passam agora a se configurar como um elemento de responsabilidade no âmbito das instituições públicas de ensino. São elementos merecedores de nossa atenção, que produzem perguntas e direcionam nosso olhar para os possíveis efeitos da atual Lei n. 12.796/2013 em relação à organização dos serviços de educação especial para essa faixa etária, considerando a ampliação da escolarização obrigatória - dos 4 aos 17 anos. 
Um segundo movimento de leitura compreendeu um olhar para a Educação Especial na Educação Infantil, a relação entre esses dois campos e a reafirmação de um espaço ainda periférico que ocupam. Espaço esse caracterizado pelo pouco investimento: seja na oferta dos serviços, nos processos de inclusão escolar, na produção do material didático/formativo para a área, na implantação das salas de recursos multifuncionais, seja na pouca pesquisa científica produzida na área, enfim, muitos são os pontos/ações.

Os dois primeiros movimentos de leitura permitiram uma compreensão contextualizada dessas duas áreas - Educação Infantil e Educação Especial - e da relação entre esses dois campos. Serviram ainda de cenário para a produção do terceiro movimento de leitura no contexto da Rede Municipal de Ensino de Santa Maria. Esse último se desdobra em três tempos de leitura, a partir da construção de três mapas-quadros.

\title{
Terceiro Movimento de Leitura: um desdobramento em três tempos...
}

\begin{abstract}
São muitas as suas formas e tipologias: ler silenciosamente, em voz alta, sozinho, em grupo; ler classificando, prevendo, traduzindo; [...] Ler é um ato solitário e simultaneamente coletivo; é particular e social; é conceber significados únicos e necessariamente compartilháveis; é situar-se num vale de letras, construindo pontos de vista. [...] Movimento incessante de reposicionamentos e releituras, de limites e possibilidades, de habitar a obra e tornar-se habitado por ela (Vasques, 2008, p.154, grifo nosso).
\end{abstract}

Considerando as múltiplas formas de leitura, na ação constante de "reposicionamentos e releituras", nosso terceiro movimento produz um desdobramento em três tempos ou modos de ler um determinado contexto: a Rede Municipal de Ensino de Santa Maria.

Um primeiro tempo apresenta nosso olhar sobre a estrutura da rede, ou seja, sobre como ela se organiza, no número de escolas; alunos (matrículas) por etapas de ensino - educação infantil e ensino fundamental; docentes; e a oferta do serviço de atendimento educacional especializado.

Como segundo tempo, analisaremos as matrículas especificamente das 20 instituições de educação infantil identificando o número de alunos da educação especial, e a oferta do serviço de atendimento educacional especializado nesses espaços.

No terceiro tempo, produzimos um mapa constituído pelos alunos da Educação Especial matriculados nas Escolas Municipais de Educação Infantil. Sinalizamos esses alunos por meio de suas matrículas, acessando seu código de registro no INEP. O código do aluno permite o conhecimento de inúmeras informações a respeito do sujeito, as quais 
envolvem, por exemplo, idade; etapa de ensino (creche ou pré-escola); frequência no atendimento educacional especializado; categorias a partir das quais está identificado no Censo Escolar. Desse modo, saímos do contingente das matrículas para o campo do sujeito, com o objetivo de pensar e refletir sobre os processos de identificação desses alunos, ao abordar o diagnóstico da criança registrado no censo escolar.

Apresentados nossos tempos de leitura, compartilhamos com o leitor os processos metodológicos constituintes do presente estudo: quais fontes? Quais processos? Que leituras?

Como pesquisadoras, iniciamos um percurso pelo universo dos dados estatístico-educacionais de âmbito nacional. Nossa principal fonte de pesquisa são os dados do Censo da Educação Básica, o qual consiste em um levantamento de dados estatístico-educacionais de âmbito nacional realizado todos os anos e coordenado pelo INEP. De acordo com esse Instituto:

\begin{abstract}
Essas informações são utilizadas para traçar um panorama nacional da educação básica e servem de referência para a formulação de políticas públicas e execução de programas na área da educação, incluindo os de transferência de recursos públicos como merenda e transporte escolar, distribuição de livros e uniformes, implantação de bibliotecas, instalação de energia elétrica. Dinheiro Direto na Escola e Fundo de Manutenção e Desenvolvimento da Educação Básica e de Valorização dos Profissionais da Educação (Brasil, 2011a, online) ${ }^{11}$.
\end{abstract}

Por outro lado, Jannuzzi (2005, p. 138) aponta um acesso crescente às informações de natureza administrativa e estatística, possibilitadas pelas novas tecnologias de informação e comunicação. Os “[...] dados estatísticos antes inacessíveis em enormes arquivos digitais passam a ser 'customizados' na forma de tabelas, mapas e modelos quantitativos construídos por usuários não especializados”.

Nossa intenção ao acessar os bancos Data Escola Brasil e o Microdados, lembrando que ambos provêm de uma mesma fonte de informações, é o de conhecer a realidade de uma determinada rede de ensino. $\mathrm{O}$ primeiro banco - Data Escola Brasil - nos ajuda na construção de uma visão mais ampla da organização da rede no que tange a sua estrutura (número de escolas, matrículas e oferta do atendimento educacional especializado); já o segundo é utilizado para rastrearmos o aluno, para olharmos no detalhe do mapa como esse aluno se constitui nessa rede... Reconhecemos que realizar um estudo tomando esses bancos como um dos elementos de análise requer trabalhar com a instabilidade presente no desenvolvimento desses dados. Os dados são obtidos por meio de um sistema educacional intitulado Educacenso. Esse preenchimento ocorre em duas etapas:

Educação \& Realidade, Porto Alegre, v. 39, n. 3, p. 745-769, jul./set. 2014.

Disponível em: <http://www.ufrgs.br/edu_realidade> 
Atos de Ler a Educação Especial na Educação Infantil

A primeira, da matrícula inicial, coleta as informações referentes às quatro grandes dimensões: escola, turma, aluno e profissional escolar em sala de aula. Para cada uma delas são coletadas informações que buscam sua caracterização. A segunda etapa de coleta é a 'Situação do Aluno' que tem por objetivo coletar as informações de rendimento (aprovado, reprovado) e movimento (transferido ou deixou de frequentar) do aluno no final do período letivo (Brasil, 2013b, p. 4).

Embora haja orientações claras sobre a forma com que os questionários devem ser preenchidos e até mesmo sobre quem deve ser o responsável pelo repasse dessas informações, os números apresentam dúvidas e muitos questionamentos. No momento em que as informações são sistematizadas pelo INEP, os dados tornam-se públicos. O grande número de informações, com inúmeras variáveis de pesquisa, exige que os dados sejam combinados a partir de um programa de estatística: Statistical Package for the Social Sciences (SPSS) ${ }^{12}$, o qual possibilita um detalhamento maior dos dados, quando comparado ao banco Data Escola Brasil, ou até mesmo às sinopses estatísticas.

Nessa direção, no universo de números, inspiradas pelo movimento da construção de diferentes mapas, pensamos e sinalizamos que "[...] é preciso saber ler para encontrar o caminho [...] se uma pessoa estuda o mapa do lugar onde mora, primeiro tem que encontrar o lugar que está ao olhar para o mapa" (Piglia, 2006, p. 14). Assim, no ato de ler a organização de um serviço em (de) uma rede, optamos por brincar com as letras, os números e as palavras. No processo de construção dos dados demarcados, o romance A História sem Fim, de Ende, possibilita-nos outro olhar...

Havia ali um grande grupo de pessoas, homens e mulheres, novos e velhos, todos vestidos da maneira mais estranha, mas sem falar. No chão havia um montão de grandes dados, que tinham letras nas seis faces. Aquelas pessoas jogavam continuamente os dados e depois observavam-nos fixamente durante muito tempo.

- Que estão fazendo? - murmurou Bastian - Que jogo é aquele? Como se chama?

- É o jogo do acaso - respondeu Argax. Acenou aos jogadores [...].

- Já não são capazes de contar histórias. Esqueceram a fala. Por isso lhes inventei esse jogo. Para passar o tempo, como você vê. E é muito simples. Pensando bem, temos de concordar que, no fundo, todas as histórias do mundo se compõem apenas de vinte e seis letras. As letras são sempre as mesmas, só a sua combinação varia. Com as letras formam-se palavras, com as palavras frases, com as frases capítulos e com capítulos histórias. Olhe o que aquilo deu! (Ende, 2000, p. 338-339). 
Tomando a lógica dessa história como um fio condutor de nosso trabalho com os dados do Censo da Educação Básica, do mesmo modo que diferentes combinações das vinte e seis letras do alfabeto constroem histórias, trabalhar com os dados de matrículas do Censo Escolar da Educação Básica também trata da construção de histórias. O banco de dados do Censo está organizado por regiões do país e seus respectivos estados a partir de quatro cadastros de dados: escola, matrícula, docente e turma. No caso do presente estudo, trabalharemos com os bancos de matrículas e docentes.

Como o jogo do acaso apresentado na história, com grandes dados, que, em vez de letras, têm números em suas seis faces, jogamos com o auxílio do SPSS. Este, a partir das combinações solicitadas, acessa o número de matrículas dos alunos de diferentes etapas e modalidade de ensino. O caminho percorrido foi o de isolar a RME/SM no universo do Estado do Rio Grande do Sul. Após, optamos por cruzar os alunos com deficiência dentro das etapas de ensino (Educação Infantil e Ensino Fundamental de nove anos) ${ }^{13}$. Na sequência, acessamos os dados das escolas municipais infantis encontradas no Data Escola Brasil, com o intuito de atentar para a matrículas dos alunos no atendimento educacional especializado. O código da escola nos possibilitou acessar o código dos alunos e, consequentemente, sua descrição no Educacenso, por exemplo, a partir de qual deficiência ele foi identificado.

\section{Três Tempos de Leitura: a construção de mapas}

Na continuidade do movimento de leitura e das diferentes formas que ela pode ganhar, refletimos agora sobre o papel do leitor dentro das dobras dos três tempos de leitura, como "[...] um leitor perante o infinito e a proliferação. Não o leitor que lê um livro, mas o leitor perdido numa rede de signos", tomadas pela possibilidade, por “[...] uma certa inclinação deliberada para ler mal, para ler fora do lugar, para relacionar séries impossíveis" (Piglia, 2006, p. 27).

Tomamos a proposta de leitura na possível construção de diferentes mapas, lembrando sempre que o mapa a ser construído está constantemente se modificando. Ainda de acordo com Piglia (2006, p. 14), "Um mapa - disse - é uma síntese da realidade, um espelho que nos guia na confusão da vida. É preciso saber ler entre as linhas para encontrar o caminho [...]".

Nessa direção, o primeiro tempo de leitura se constitui a partir do primeiro mapa e nos possibilita um olhar mais amplo relativo à oferta $\mathrm{e}$ à organização do ensino na Rede Municipal de Santa Maria.

Nos últimos anos, no âmbito da Rede Municipal de Ensino de Santa Maria, expressivas ações com a intencionalidade de garantir a escolarização de todos os alunos têm sido feitas. Conforme a Proposta Pedagógica das Diretrizes Curriculares Municipais (2008, p. 12), “[...] a partir de 1997, na Rede Municipal de Ensino de Santa Maria, teve início

Educação \& Realidade, Porto Alegre, v. 39, n. 3, p. 745-769, jul./set. 2014.

Disponível em: <http://www.ufrgs.br/edu_realidade> 
o processo de transformação em relação à organização do atendimento aos alunos com necessidades educacionais especiais na área de Educação Especial".

Essa afirmação encontra consonância com o processo de municipalização do ensino, iniciado após publicação da LDB n. 9.394/96. Como apontam Prieto (2006; 2009) e Garcia (2009), essa (re)definição de incumbências fez com que os municípios se ocupassem também da oferta do atendimento educacional aos alunos da educação especial pertencentes a essas etapas da escolarização. Dessa forma, no contexto das diferentes redes municipais de ensino, foi criada e/ou mantida uma estrutura para a educação especial; as novas determinações provocaram uma reorganização das redes de ensino, tendo em vista o surgimento de novas demandas, competências e responsabilidades.

Assim, acompanhamos uma atuação mais enfática no campo da educação especial a partir do processo de municipalização do ensino. Porém, no âmbito desta rede, a partir do ano de 2001, quando a Administração Popular assume o governo municipal, é que visualizamos a execução de um conjunto de ações produtoras de novos contornos e caracterizações à educação especial. Isso se deve aos próprios pressupostos que embasam a proposta de governo e à estreita relação estabelecida entre a Secretaria de Município da Educação e a Secretaria de Educação Especial do Ministério da Educação (SECADI/MEC).

A Administração Popular exerceu dois mandatos em Santa Maria, e, neste período, de 2001 a 2008, a gestão da educação especial organizou-se por meio do Eixo Pedagógico Inclusão ${ }^{14}$. Tal eixo teve como objetivo principal "[...] articular as ações de forma integrada com todas as modalidades de ensino", bem como “[...] esclarecer, subsidiar e acompanhar o processo de aprendizagem e desenvolvimento dos alunos em todos os níveis, de acordo com suas peculiaridades, tendo como princípio básico o respeito à diversidade" (Müller; Villagran, 2008, p. 5).

Na esteira das ações desenvolvidas pelo município nesse período, merecem destaque a ampliação progressiva de recursos humanos em educação especial, a ampliação do número de matrículas de alunos em situação de inclusão, o fechamento das classes especiais em $2007^{15}$ e a construção das Diretrizes Curriculares Municipais em Educação Especial (Bridi, 2011). E, ainda, no ano de 2003, a Rede Municipal de Ensino de Santa Maria aderiu ao Programa de Educação Inclusiva da SECADI/ MEC - Educação Inclusiva: Direito à Diversidade, tornando-se um dos municípios-polo desse programa. Desde 2003, são ofertados anualmente aos professores da rede pública de ensino cursos de formação na área da educação especial/educação inclusiva.

As ações descritas pela Secretaria de Município da Educação/ Educação Inclusiva para a efetivação de políticas de inclusão escolar no sistema comum de ensino, em boa parte, estão ligadas a programas e ações do Governo Federal, ações tais como aquisição de salas de recur- 
sos multifuncionais por intermédio do Programa de Implantação das Salas de Recursos Multifuncional; ações de formação de professores por meio do Programa Educação Inclusiva: Direito à Diversidade; formação de professores para o Atendimento Educacional Especializado por meio do Programa de Formação Continuada dos Professores em Educação Especial; Programa Escola Acessível ${ }^{16}$; Programa BPC na Escola ${ }^{17}$. Enfim, segundo Peripolli (2010), objetiva-se a construção e execução de planos e projetos em consonância com as diretrizes propostas pela Política Nacional de Educação Especial na Perspectiva da Educação Inclusiva (2008).

A Tabela 1 apresenta informações atuais da Rede de Ensino. Nesta tabela, podemos observar dados referentes ao número de escolas; à oferta do atendimento educacional especializado; à matrícula dos docentes, alunos e alunos da educação especial por etapa de ensino.

Tabela 1 - Rede Municipal de Ensino do Município de Santa Maria Etapa de Ensino - Educação Infantil e Ensino Fundamental

\begin{tabular}{|c|c|c|c|c|c|}
\hline $\begin{array}{c}\text { ETAPA } \\
\text { ENSINO } \\
\end{array}$ & EsCOLAS & $\begin{array}{c}\text { ESCOLAS QUE } \\
\text { OFERTAM O AEE } \\
\end{array}$ & $\begin{array}{c}\text { Matrí́culas } \\
\text { GeRAIS }\end{array}$ & DOCENTES & $\begin{array}{c}\text { AluNOS DA } \\
\text { EDUC. EsPECIAL }\end{array}$ \\
\hline INFANTIL & $\begin{array}{l}19 \text { urbanas } \\
\text { 01 rural }\end{array}$ & 05 urbanas & 3.965 & 251 & 53 \\
\hline $\begin{array}{l}\text { FUNDAMENTAL } \\
\text { (9 anos) }\end{array}$ & $\begin{array}{l}43 \text { urbanas } \\
9 \text { rurais }\end{array}$ & $\begin{array}{c}05 \text { rurais } \\
32 \text { urbanas }\end{array}$ & 12.996 & 2.781 & 516 \\
\hline Total & 72 & 42 & 16.961 & 3.032 & 569 \\
\hline
\end{tabular}

Fonte: Elaboração das autoras com base nos bancos Data Escola Brasil (2013) e nos microdados (2012) do Censo da Educação Básica (Brasil, MEC/INEP, 2012; 2013a).

De acordo com os dados preliminares do Censo da Educação Básica de $2013^{18}$, a Rede Municipal de Ensino do Município de Santa Maria/RS é composta por 72 escolas de ensino regular: 62 escolas urbanas e 10 escolas rurais, sendo 20 instituições de educação infantil (01 rural) e 52 de ensino fundamental (09 rurais). Do universo das escolas de ensino fundamental, 29 ofertam educação infantil. No que diz respeito ao corpo docente da rede, temos 3.032 professores, sendo que 251 atuam na etapa da educação infantil e 2.781 no ensino fundamental. Vale salientar que estamos trabalhando aqui com o dado de matrícula dos docentes, de modo que um mesmo docente pode representar duas matrículas (dois contratos com a rede). Assim, no que compete ao tipo de contratação, o registro de matrículas mostra um número de 2.937 concursados, 54 contratos temporários e 41 CLT (Consolidação das Leis de Trabalho).

Em relação aos dados de matrículas dos alunos, a rede conta com um total de 16.961 alunos; destes, 3.965 matrículas na etapa da educação infantil e 12.996 matrículas na etapa do ensino fundamental. Destaque-se que as matrículas em instituições específicas de educação

Educação \& Realidade, Porto Alegre, v. 39, n. 3, p. 745-769, jul./set. 2014.

Disponível em: <http://www.ufrgs.br/edu_realidade> 
Atos de Ler a Educação Especial na Educação Infantil

infantil computam o número de 2.907, enquanto temos 1.058 alunos na educação infantil ofertada nas escolas de ensino fundamental. Na área de educação especial, a rede apresenta 569 alunos identificados como público-alvo da educação especial; destes, 53 encontram-se matriculados na educação infantil e 516 no ensino fundamental.

Ao pensarmos em percentuais entre o total de matrícula e o número de alunos em situação de inclusão, na Educação Infantil temos aproximadamente 1,33\% e no Ensino Fundamental 3,97\%, reafirmando a necessidade de ampliação do acesso à escola dos alunos da Educação Especial na Educação Infantil.

O segundo tempo de leitura se constitui a partir da especificidade da educação infantil, ao focar nas matrículas das 20 instituições que a ofertam, construindo um segundo mapa referente aos alunos identificados como alunos da educação especial. Neste universo, temos 36 alunos da Educação Especial matriculados em Escolas Municipais Infantis, e 22 matrículas no atendimento educacional especializado, nas 5 escolas infantis que contam com o serviço.

Tabela 2 - Rede Municipal de Ensino do Município de Santa Maria Matrículas nas Instituições de Educação Infantil

\begin{tabular}{|c|c|c|c|}
\hline EDUCAÇÃo INFANTIL & Matrí́culas & Alunos DA EdUc. EsPECIAL & $\begin{array}{c}\text { ATENDIMENTO EDUCACIONAL } \\
\text { ESPECIALIZADO }\end{array}$ \\
\hline CRECHE & 1.371 & 9 & \\
\hline Pré-ESCOLA & 1.536 & 27 & 22 \\
\hline TOTAL & 2.907 & 36 & \\
\hline
\end{tabular}

Ao transformarmos os dados em percentuais, entre o total de matrículas na creche e na pré-escola e o total de alunos da Educação Especial em cada uma dessas etapas, temos um percentual de $0,65 \%$ de alunos matriculados na creche e de $1,75 \%$ matriculados na pré-escola. Os dados apontam uma concentração de matrículas dos alunos da Educação Especial na pré-escola (27 alunos) em comparação à creche (9 alunos). Essa informação poderia estar vinculada ao ingresso mais tardio na escola dos alunos da Educação Especial ou relacionados à própria produção dos processos de identificação e diagnóstico desses alunos. Segundo Bridi (2011), com frequência, os alunos da Educação Especial vivenciam esse processo ao longo da trajetória escolar, sendo que esta produção concentra-se nos anos iniciais do Ensino Fundamental. No caso da deficiência mental, apresenta-se diretamente vinculada à construção dos conteúdos e aprendizagens escolares, em especial da leitura, escrita e cálculo.

Nem todos os alunos identificados parecem frequentar o Atendimento Educacional Especializado, na medida em que temos 36 alu- 
nos cadastrados, e o registro de 22 alunos que frequentam o serviço. Podemos pensar que 14 alunos ainda não recebem o atendimento ou que podem estar frequentando esse serviço em outros espaços e instituições especializadas, considerando que historicamente os serviços de Educação Especial destinados aos pequenos ficaram a cargo dessas instituições.

Segundo dados colhidos com a Secretaria Municipal de Educação, atualmente 39 Educadores Especiais trabalham na referida rede de ensino. $\mathrm{O}$ atendimento educacional especializado, realizado nas cinco escolas infantis, fica a cargo de três educadoras especiais, que dividem sua carga horária de atendimento por escola: Educadora A (30h); Educadora B (20h, 10h e 10h) e Educadora C (10h).

O terceiro tempo de leitura se constitui com os sujeitos. A partir do código do aluno, desenhamos um mapa dos 36 alunos identificados nas escolas infantis a partir das informações sobre idade, modalidade de ensino e diagnóstico.

Tabela 3 - Alunos da Educação Especial Matriculados na Educação Infantil

\begin{tabular}{|c|c|c|}
\hline IDADE & MODALIDAdE DE ENSINO & Diagnóstico \\
\hline 6 & PRÉ-ESCOLA & $\mathrm{DM}$ \\
\hline 5 & PRÉ-ESCOLA & Def. Física; Def. Mental e Def. Múltipla \\
\hline 5 & PRÉ-ESCOLA & Def. Física; Def. Mental e Def. Múltipla \\
\hline 4 & CRECHE & Autismo \\
\hline 4 & PRÉ-ESCOLA & Def. Mental \\
\hline 5 & PRÉ-ESCOLA & Def. Mental \\
\hline 5 & PRÉ-ESCOLA & Def. Mental \\
\hline 5 & PRÉ-ESCOLA & Def. Mental \\
\hline 4 & PRÉ-ESCOLA & Def. Mental \\
\hline 2 & CRECHE & Baixa Visão; Def. Física e Def. Múltipla \\
\hline 5 & PRÉ-ESCOLA & Autismo \\
\hline 5 & PRÉ-ESCOLA & Def. Mental \\
\hline 6 & PRÉ-ESCOLA & Def. Física \\
\hline 6 & PRÉ-ESCOLA & Autismo \\
\hline 2 & CRECHE & Baixa Visão \\
\hline 4 & PRÉ-ESCOLA & Def. Auditiva \\
\hline 5 & PRÉ-ESCOLA & Transtorno Desintegrativo da Infância \\
\hline 5 & PRÉ-ESCOLA & Baixa Visão \\
\hline 5 & PRÉ-ESCOLA & Autismo \\
\hline 6 & PRÉ-ESCOLA & Transtorno Desintegrativo da Infância \\
\hline 2 & CRECHE & Def. Física \\
\hline 4 & CRECHE & Transtorno Desintegrativo da Infância \\
\hline 4 & CRECHE & Transtorno Desintegrativo da Infância \\
\hline 5 & PRÉ-ESCOLA & Transtorno Desintegrativo da Infância \\
\hline 3 & CRECHE & Def. Física \\
\hline
\end{tabular}

Educação \& Realidade, Porto Alegre, v. 39, n. 3, p. 745-769, jul./set. 2014.

Disponível em: <http://www.ufrgs.br/edu_realidade> 
Atos de Ler a Educação Especial na Educação Infantil

\begin{tabular}{ccc}
$\mathbf{3}$ & CRECHE & Def. Mental \\
$\mathbf{5}$ & PRÉ-ESCOLA & Baixa Visão \\
$\mathbf{5}$ & PRÉ-ESCOLA & Def. Física \\
$\mathbf{4}$ & PRÉ-ESCOLA & Def. Física; Def. Mental e Def. Múltipla \\
$\mathbf{6}$ & PRÉ-ESCOLA & Transtorno Desintegrativo da Infância \\
$\mathbf{6}$ & PRÉ-ESCOLA & Def. Mental \\
$\mathbf{6}$ & PRÉ-ESCOLA & Def. Auditiva \\
\hline $\mathbf{5}$ & PRÉ-ESCOLA & Austismo \\
$\mathbf{6}$ & PRÉ-ESCOLA & Autismo \\
$\mathbf{3}$ & CRECHE & Baixa Visão; Def. Auditiva; Def. Múltipla \\
$\mathbf{6}$ & PRÉ-ESCOLA & Def. Física; Def. Mental e Def. Múltipla \\
\hline Fonte: Elaboração das autoras com base no banco dos Microdados (2012) do Censo \\
\multicolumn{3}{r}{ da Educação Básica (Brasil, MEC/INEP, 2012; 2013a). }
\end{tabular}

Como já referido anteriormente, o maior número de alunos encontra-se na pré-escola. Porém, merece consideração a presença de três alunos com 4 anos na creche, já apontando para o início de uma dissonância idade-ano escolar. Essa dissonância se faz presente também ao olharmos os dados da pré-escola. Observa-se a presença de 9 alunos com 6 anos nesta etapa de ensino. Considerando que no município de Santa Maria/RS todas as escolas já implementaram o ensino de nove anos, as crianças de seis anos deveriam estar frequentando o primeiro ano do Ensino Fundamental, constituindo-se a pré-escola de alunos com 4 e 5 anos de idade. Merece ser considerado ainda que esses alunos de 4 anos na creche e 6 anos na pré-escola pertencem, em sua maioria, a quadros diagnósticos de Transtorno Desintegrativo da Infância (4 alunos); Autismo (3 alunos) e Deficiência Mental (2 alunos). Historicamente essas categorias de alunos lançaram grandes desafios no que tange aos processos diagnósticos, como também às possibilidades de escolarização. Por constituírem-se em categorias diagnósticas que não implicam perda de função motora ou sentidos (visão, audição), não estão explicitamente visíveis. Envolvem sempre uma dimensão relacional daquele (profissional) que olha e lê o comportamento e as características desses sujeitos atribuindo (ou não) uma categoria diagnóstica. Para além desse aspecto, autores como Nunes e Ferreira (1993); Anache (2001); Vasques (2008); Bridi (2011) têm problematizado as relações entre diagnóstico e escolarização, no sentido de que o primeiro tem servido para definir, organizar e delimitar as práticas pedagógicas, com frequência, limitando-as. Dessa forma, o diagnóstico tem definido tanto a intervenção pedagógica como a escolha dos espaços escolares que esses alunos devem frequentar.

Ao olharmos para os 36 alunos identificados nas escolas infantis, novamente as três categorias se repetem. Temos 9 alunos com Deficiência Mental; 6 alunos com Autismo; e 6 alunos com Transtorno Desintegrativo da Infância. Nota-se que o maior percentual de alunos corresponde a crianças com Deficiência Mental. Em relação ao fluxo de matrículas dos alunos da educação especial, no território nacional, esse 
dado apresenta consonância com os dados estatísticos do governo federal MEC/INEP. Em análise realizada por Meletti e Bueno (2013), no período de 1998 a 2010, a categoria Deficiência Mental apresenta o maior percentual de alunos em todos os anos, chegando a abranger mais do que 50\% do total de alunos da Educação Especial. Para Baptista (2008), o reconhecimento de que categoria abrange o maior número de alunos é fundamental para a construção de diretrizes referentes à oferta e ao acompanhamento pedagógico desses alunos em processo de inclusão escolar.

Os modos pelos quais estamos vivenciando os processos de identificação e diagnóstico dos alunos da educação especial no contexto escolar merecem consideração. Conforme as orientações para o preenchimento do Censo Escolar, não é necessária a presença do diagnóstico clínico.

É necessário o laudo médico (diagnóstico clínico) para informar um estudante com deficiência, transtornos globais do desenvolvimento ou altas habilidades?

Não. O Censo Escolar exige que os dados informados possam ser comprovados. Assim, para cadastro de estudantes público alvo da educação especial, é necessário que o professor do atendimento educacional especializado AEE - elabore o plano de AEE para, a partir disso, organizar e ofertar o devido atendimento ao estudante público alvo da educação especial [...] É importante notar que o Censo Escolar é base de dados da educação, cujas ações não necessitam de laudo médico para serem efetivadas (Brasil, 2011c, online) ${ }^{19}$.

Esta orientação está presente desde 2011, e temos vivenciado, no universo escolar, a decisão de ingresso e frequência ao atendimento educacional especializado a partir da ação do professor especializado que atua nesse serviço. É importante considerar que a esse professor cabe a decisão educacional e pedagógica sobre a frequência ou não dos alunos nos diferentes espaços escolares (nesse caso, no atendimento educacional especializado). Porém, na medida em que o aluno ingressa no referido serviço, é necessário que seja identificado no Censo Escolar e, dessa forma, os processos diagnósticos se produzem no contexto escolar. No contexto da referida rede de ensino, essa temática foi objeto de atenção e pesquisa de Bridi (2011), ao problematizar a produção dos processos de identificação e diagnóstico dos alunos com deficiência mental a partir do atendimento educacional especializado. Vale ressaltar que esta temática também tem-se constituído como objeto de interesse de outros autores, como apontam os estudos de Jesus e Aguiar (2012).

Outro elemento de análise, a partir das informações na Tabela 3, refere-se à tríplice marcação de alguns alunos no Censo Escolar. É possível observar que essa tríplice marcação ocorre com os alunos com

Educação \& Realidade, Porto Alegre, v. 39, n. 3, p. 745-769, jul./set. 2014.

Disponível em: <http://www.ufrgs.br/edu_realidade> 
Atos de Ler a Educação Especial na Educação Infantil

deficiência múltipla, que são identificados por meio da deficiência múltipla e das demais categorias diagnósticas que apresentam, o que acarreta uma discrepância entre o número geral de matrícula dos alunos da educação especial.

\section{Considerações sobre a Leitura de uma Realidade}

No campo da leitura não há pertinência de objetos: o verbo ler, aparentemente muito mais transitivo do que o verbo falar, pode ser saturado, catalisado, com mil objetos diretos: leio textos, imagens, cidades, rostos, gestos, cenas, etc. Esses objetos são tão variados que não posso unificá-los sob nenhuma categoria substancial, nem mesmo formal; apenas posso encontrar neles uma unidade intencional: o objeto que eu leio é fundado apenas pela minha intenção de ler; ele é simplesmente: para ler, legendum, pertencendo a uma fenomenologia, não a uma semiologia (Barthes, 2004, p. 32, grifos do autor).

Em sintonia com Barthes, destacamos nossa intencionalidade de ler uma realidade. $\mathrm{O}$ ato de produzir uma leitura da Educação Especial na Educação Infantil na RME/SM foi constituído por diferentes e interligados movimentos, que permitiram uma compreensão das relações entre esses dois campos - Educação Infantil e Educação Especial e de suas manifestações no contexto da RME/SM. O reconhecimento dos avanços da Educação Infantil no âmbito legal e da ampliação do número de matrículas dos alunos nesta modalidade de ensino intensificam a necessidade de outros/novos movimentos que reconfigurem e consolidem essa primeira etapa de ensino da Educação Básica. O atual momento da Educação Infantil, compondo a escolarização obrigatória, já anuncia novas transformações quanto à oferta do ensino aos pequenos, que poderão traduzir-se na ampliação do acesso ao ensino, nas diretrizes de formação do profissional da educação infantil, nas formas de organização e gestão do trabalho pedagógico entre outros... É nesse contexto que se inserem os alunos da Educação Especial e a oferta dos serviços de atendimento especializado. Na RME/SM, é possível perceber a necessidade de se ampliar e solidificar esses serviços para essa modalidade de ensino. Um olhar atento para os processos de identificação e diagnósticos, para as ações de preenchimento do Censo Escolar; para as dissonâncias idade-ano escolar, que tão precocemente começam a se formar, faz-se necessário. Anunciamos como outros movimentos de leitura um olhar para além dos dados numérico-estatístico. Movimentos que possibilitem uma aproximação com o contexto escolar e com a prática pedagógica que permeia a ação das educadoras especiais no atendimento à primeira infância.

Recebido em 12 de março de 2014 Aprovado em 10 de maio de 2014 


\section{Notas}

1 Entendemos como alunos da educação especial o público-alvo descrito na atual Política Nacional de Educação Especial na Perspectiva da Educação Inclusiva (Brasil, 2008). Sendo esses alunos com deficiência, transtornos globais do desenvolvimento, altas habilidades/superdotação.

2 Reconhecemos o presente tempo histórico de ressignificação da Educação Infantil, anteriormente demarcada pela LDB/96 como creche ( 0 a 3 anos de idade) e pré-escola (4 a 6 anos de idade). Com a atual Lei n. 12.796/2013, a Educação Infantil passa a ser referendada como creche ( 0 a 3 anos) e pré-escola ( 4 a 5 anos). A criança de seis anos, antes vinculada à Educação Infantil, passa a ser aluna do Ensino Fundamental com a implementação do ensino de nove anos. Portanto, no decorrer do texto, quando falarmos em pré-escola, estaremos nos referindo às crianças de 4 a 5 anos de idade.

3 De acordo com o INEP/MEC, a designação do Ensino Fundamental de nove anos descreve anos iniciais ( $1^{\circ}$ ao $5^{\circ}$ ano) e anos finais ( $6^{\circ}$ ao $9^{\circ}$ ano). Já o Ensino Fundamental de oito anos designa anos iniciais ( $1^{\mathrm{a}}$ a $4^{\mathrm{a}}$ série) e anos finais ( $5^{\mathrm{a}}$ a $8^{a}$ série). Fonte: Data Escola Brasil (<http://www.dataescolabrasil.inep.gov. br/dataEscolaBrasil >).

4 Para maiores informações sobre a oferta de cada turma e a definição de seu público, consultar documento do PARFOR. Disponível em: <http://capes.gov. br/educacao-basica/parfor>.

5 Disponível em: <http://www.capes.gov.br/educacao-basica/parfor>. Acesso em: 18 out. 2013.

6 A sigla SEESP refere-se à antiga Secretaria de Educação Especial, extinta em 2011. Em substituição, temos a criação da SECADI - Secretaria de Educação Continuada, Alfabetização, Diversidade e Inclusão. Neste artigo, usaremos a sigla SEESP sempre que referirmos materiais e documentos publicados pela antiga Secretaria de Educação Especial.

7 O primeiro volume da coleção conta com um caderno intitulado Introdução.

8 Os serviços itinerantes na educação infantil “[...] poderão ser desenvolvidos por professor itinerante especializado em educação especial e infantil, que participará da observação e do acompanhamento do processo de desenvolvimento e aprendizagem nas atividades escolares, avaliará e ajudará a elaborar objetivos [...]" (Brasil, 2006, p. 31).

9 Os serviços de intervenção precoce têm por objetivo "[...] o desenvolvimento integral do educando nos seus aspectos físicos, psicoafetivos, cognitivos, sociais e culturais, priorizando o apoio e suporte à família e a inclusão dessas crianças em creches na comunidade. Os programas de intervenção precoce do nascimento aos três anos de idade são imprescindíveis para a promoção das potencialidades e aquisição de habilidades e competências [...]" (Brasil, 2006, p. 31-32).

10 Disponível em: <http://painel.mec.gov.br/painel/detalhamentoIndicador/ detalhes/pais/secid/2 2 . Acesso em: 18 out. 2013.

11 Disponível em: <http://portal.inep.gov.br/basica-censo>. Acesso em: 18 out. 2013.

12 No presente estudo a versão do programa utilizada foi 17.0.

Educação \& Realidade, Porto Alegre, v. 39, n. 3, p. 745-769, jul./set. 2014.

Disponível em: <http://www.ufrgs.br/edu_realidade> 
13 De acordo com os dados, a rede municipal não possui turmas do ensino fundamental de oito anos.

14 Neste período, a Educação Especial ficou sob a responsabilidade de duas professoras com formação específica na área.

15 Na Rede Municipal de Ensino de Santa Maria, até o ano de 2007, existiam quatro classes especiais em funcionamento, após um processo de discussão entre a gestão, a comunidade escolar e as famílias, as classes especiais foram fechadas e, os alunos, encaminhados para os espaços de ensino comum. No lugar das classes especiais, foi assegurada a oferta do Atendimento Educacional Especializado.

16 O Programa Escola Acessível busca adequar o espaço físico das escolas, visando à promoção da acessibilidade nas redes públicas de ensino. No âmbito da RME de Santa Maria, 21 escolas já foram contempladas com esse programa (Brasil, 2011b).

17 Refere-se ao Programa de Benefício de Prestação Continuada (BPC) na Escola, que tem por objetivo acompanhar e monitorar o acesso e a permanência na escola das pessoas com deficiência, beneficiárias do BPC, até 18 anos, por meio da articulação das políticas de educação, saúde, assistência social e direitos humanos (Brasil, 2011b).

18 Os dados do Censo Escolar foram coletados nas informações estatísticas do Instituto Nacional de Estudos e Pesquisas Educacionais Anísio Teixeira (INEP), via banco de dados intitulado Data Escola Brasil. Acesso em: 08, 09 e 10 de outubro de 2013.

19 Acesso em: 20 out. 2013.

\section{Referências}

ANACHE, Adriana. Reflexões sobre o Diagnóstico Psicológico da Deficiência Mental utilizado em Educação Especial. In: 24ª REUNIÃO ANUAL DA ANPED, 2001, Caxambu. Anais... Caxambu: 2001.

BAPTISTA, Claudio Roberto. A Política nacional de educação especial no Brasil: passos para uma perspectiva inclusiva? In: MARTINS, Lucia; PIRES, José; PIRES, Glaucia; MELO, Francisco (Org.). Práticas Inclusivas no Sistema de Ensino e em Outros Contextos. Natal: EDUFRN, 2008. P. 19-33.

BAPTISTA, Claudio Roberto. Ação Pedagógica e Educação especial: a sala de recursos como prioridade na oferta de serviços especializados. Revista Brasileira de Educação Especial, Marília, v. 17, p. 59-76, maio/ago. 2011.

BARTHES, Roland. O Rumor da Língua. São Paulo: Martins Fontes, 2004.

BENINCASA, Melina Chassot. Educação Especial e Educação Infantil: uma análise de serviços especializados no Município de Porto Alegre. 2011. $123 \mathrm{f}$. Dissertação (Mestrado em Educação) - Programa de Pós-Graduação em Educação, Universidade Federal do Rio Grande do Sul, Porto Alegre, 2011.

BRASIL. Ministério da Educação. Rede Nacional de Formação Continuada de Professores. Brasília, DF, 2014. Disponível em: <http://portal.mec.gov.br/index. php?option=com_content\&view=article \&id=231\&Itemid=332>. Acesso em: 03 mar. 2014.

BRASIL. Ministério da Educação. Instituto Nacional de Estudos e Pesquisa Educacional Anísio Teixeira (INEP). Censo Escolar da Educação Básica - Fol- 
der. Brasília: MEC/INEP, 2013b. Disponível em: < http://download.inep.gov.br/ educacao_basica/educacenso/documentos/2013/folder_censo_escolar_educacao_basica_2013.pdf >.Acesso em: 18 out. 2013.

BRASIL. Ministério da Educação. Painel de Controle do MEC/SIMEC: salas de recursos multifuncionais e kits de atualização com implantação iniciada. Brasília: MEC/INEP, 2013c. Disponível em: <http://painel.mec.gov.br/painel/detalhamentoIndicador/detalhes/pais/secid/2>. Acesso em: 18 out. 2013.

BRASIL. Coordenação de Aperfeiçoamento de Pessoal de Nível Superior (CAPES). Plano Nacional de Formação de Professores da Educação Básica - PARFOR. Brasília, DF, 2013d. Disponível em: <http://capes.gov.br/educacao-basica/ parfor $>$. Acesso em: 18 out. 2013.

BRASIL, Ministério da Educação. Lei n. 12.796/2013, de 04 de abril de 2013. Altera a Lei n. 9.394, de 20 de dezembro de 1996. Diário Oficial [da República Federativa do Brasil], Brasília, DF, 04 abr. 2013e.

BRASIL. Instituto Nacional de Estudos e Pesquisas Educacionais Anísio Teixeira (INEP). Censo Escolar. Brasília, DF: MEC/INEP, 2011a. Disponível em: <http:// portal.inep.gov.br/basica-censo>. Acesso em: 18 out. 2013.

BRASIL. Ministério da Educação. Secretaria de Educação Continuada, Alfabetização, Diversidade e Inclusão. Programa Escola Acessível. Brasília, 2011b. Disponível em: <http://portal.mec.gov.br/index.php?option=com_content\&view= article\&id=12293\&Itemid=590>. Acesso em: 20 out. 2013.

BRASIL. Instituto Nacional de Estudos e Pesquisas Educacionais Anísio Teixeira (INEP). Educacenso. Educação Especial: perguntas frequentes. Brasília, 2011c. Disponível em: <http://portal.inep.gov.br/web/educacenso/educacao-especial>. Acesso em: 20 out. 2013.

BRASIL. Instituto Nacional de Estudos e Pesquisas Educacionais Anísio Teixeira (INEP). Censo da Educação Básica: 2012 - resumo técnico. Brasília: MEC/ INEP, 2013a. Disponível em: <http://download.inep.gov.br/educacao_basica/ censo_escolar/resumos_tecnicos/resumo_tecnico_censo_educacao_basica_2012.pdf>. Acesso em: 18 out. 2013.

BRASIL. Conselho Nacional de Educação. Câmara de Educação Básica. Resolução CNE/CEB n. 04, de 2 de outubro de 2009. Institui Diretrizes Operacionais para o Atendimento Educacional Especializado na Educação Básica, modalidade Educação Especial. Brasília, DF, 2009.

BRASIL, Ministério da Educação. Secretaria de Educação Especial. Política Nacional de Educação Especial na Perspectiva da Educação Inclusiva. Brasília: MEC, SEESP, jan. 2008.

BRASIL, Ministério da Educação. Secretaria de Educação Especial. Educação Infantil: saberes e práticas da inclusão. V. Introdução. Brasília: 2006.

BRASIL. Conselho Nacional de Educação. Câmara de Educação Básica. Resolução CNE/CEB n. 02, de 11 de setembro de 2001. Diretrizes Nacionais para a Educação Especial na Educação Básica, 2001.

BRASIL. Lei n. 9.394, de 20 de dezembro de 1996. Estabelece as diretrizes e bases da educação nacional. Diário Oficial [da República Federativa do Brasil], Brasília, DF, v. 134, n. 248, 23 dez. 1996. Disponível em: <http://www.planalto.gov.br/ ccivil_03/leis/19394.htm>. Acesso em: 18 out. 2013.

BRIDI, Fabiane Romano de Souza. Processos de Identificação e Diagnóstico: os alunos com deficiência mental no contexto do atendimento educacional especializado. 2011. 210 f. Tese (Doutorado em Educação) - Programa de Pós- 
Atos de Ler a Educação Especial na Educação Infantil

-Graduação em Educação, Universidade Federal do Rio Grande do Sul, Porto Alegre, 2011.

BUENO, José Geraldo Silveira; MELETTI, Silvia Márcia Ferreira. Educação Infantil e Educação Especial: uma análise dos indicadores educacionais brasileiros. Revista Contrapontos - Eletrônica, v. 11, n. 3, p. 278-287, set./dez. 2011.

CAMPOS, Maria Malta; FÜLLGRAF, Jodete; WIGGERS, Verena. A Qualidade da Educação Infantil brasileira: alguns resultados de pesquisa. Cadernos de Pesquisa, São Paulo, v. 36, n. 127, p. 87-128, jan./abr. 2006.

CAMPOS, Maria Malta; ESPOSITO, Yara Lúcia; BHERING, Eliana; GIMENES, Nelson; ABUCHAIM, Beatriz. A Qualidade da Educação Infantil: um estudo em seis capitais brasileiras. Cadernos de Pesquisa, São Paulo, v. 41, n. 142, p. 20-54, jan./abr. 2011.

CRUZ, Silvia. As conquistas legais e os desafios da prática. In: $1^{\circ}$ SIMPÓSIO NACIONAL DE EDUCAÇ̃̃O BÁSICA, 2006. Brasília. Anais... Brasília, 2006.

ENDE, Michael. A História sem Fim. São Paulo: Martins Fontes, 2000.

GARCIA, Rosalba Maria Cardoso; LOPEZ, Graziela Maria Beretta. Políticas de Educação Inclusiva no Brasil: uma análise da Educação Especial na Educação Infantil (2000-2010). In: 34 REUNIÃO DA ANPED, 2011, Centro de Convenções de Natal - RN, 2011.

GARCIA, Rosalba Maria Cardoso. Política de Educação Inclusiva e Trabalho Pedagógico: uma análise do modelo de educação especial na educação básica. In: BAPTISTA, Claudio; JESUS, Denise Meyrelles. Avanços em Políticas de Inclusão: o contexto da educação especial no Brasil e em outros países. Porto Alegre: Mediação, 2009. P. 123-138.

JANNUZZI. Paulo de Martino. Indicadores para Diagnóstico, Monitoramento e Avaliação de Programas Sociais no Brasil. Revista do Serviço Público - Eletrônica, Brasília, v. 56, n. 2, p.137-160, abr./jun. 2005.

JESUS, Denise Meyrelles; AGUIAR, Ana Marta Bianchi de Aguiar. O Calcanhar de Aquiles: do mito grego ao desafio cotidiano da avaliação inicial nas salas de recursos multifuncionais. Revista Educação Especial, v. 25, n. 44, set./dez. 2012. Disponível em: <http://cascavel.ufsm.br/revistas/ojs2.2.2/index.php/educacaoespecial/article/view/6532/pdf_1>. Acesso em: 20 out. 2013.

MANGUEL, Alberto. Uma História da Leitura. São Paulo: Companhia das Letras, 1997.

MELETTI, Silvia Márcia Ferreira; BUENO, José Geraldo Silveira (Org.). Políticas Públicas, Escolarização de Alunos com Deficiência e a Pesquisa Educacional. Araraquara: Junqueira \& Marin, 2013.

MÜLLER, Marizete; VILLAGRAN, Valquirea. Educação Inclusiva na Rede Municipal de Ensino de Santa Maria. Revista Eletrônica Educação Cidadã, Santa Maria, Secretaria do Município de Educação, v. 1, n. 1, 2008. Disponível em: <http:// www.santamaria.rs.gov.br/smed/index.php?secao $=$ revista\&edicao $=13>$. Acesso em: 20 out. 2013 .

NUNES, Leila; FERREIRA, Julio. Deficiência Mental: o que as pesquisas têm revelado. Revista em Aberto, Brasília, Ano 13, n. 60, out/dez. MEC/INEP, 1993. P. 36-81.

OLIVEIRA, Ivone Martins de; PADILHA, Anna Maria Lunardi. Atendimento Educacional Especializado para Crianças de Zero a Três Anos. In: JESUS, Denise Meyrelles de; BAPTISTA, Claudio Roberto; CAIADO, Katia Regina Moreno (Org.). Prática Pedagógica na Educação Especial: multiplicidade do atendimento educacional especializado. Araraquara: Junqueira \& Marin, 2013. P. 197-218. 
PERIPOLLI, Arlei. Um Caminho Edificante da Educação Inclusiva no Município de Santa Maria/RS. In: I SEMINÁRIO DE POLÍTICAS DE INCLUSÃO ESCOLAR DO RIO GRANDE DO SUL, Porto Alegre. Anais... Porto Alegre: UFRGS/NEPIE, 2010. 1 CD-ROM.

PIGLIA, Ricardo. O Último Leitor. São Paulo: Companhia das Letras, 2006.

PRIETO, Rosângela Gavioli. Pesquisa sobre Políticas de Atendimento Escolar a Alunos com Necessidades Educacionais Especiais com Base em Fontes Documentais. In: JESUS, Denise Meyrelles; BAPTISTA, Claudio Roberto; VICTOR, Sonia Lopes (Org.). Pesquisa e Educação Especial: mapeando produções. Vitória: Edufes, 2006. P. 41-59.

PRIETO, Rosângela Gavioli. Educação Especial em Municípios Paulista: histórias singulares ou tendência unificadora? In: BAPTISTA, Claudio; JESUS, Denise Meyrelles. Avanços em Políticas de Inclusão: o contexto da educação especial no Brasil e em outros países. Porto Alegre: Mediação, 2009. P. 57-78.

SANTA MARIA, Secretaria de Município da Educação. Proposta Pedagógica das Diretrizes Curriculares Municipais. Santa Maria: Secretaria de Município da Educação, 2008.

VASQUES, Carla Karnoppi. Alice na Biblioteca Mágica: uma leitura sobre o diagnóstico e a escolarização de crianças com autismo e psicose infantil. 2008. 219 f. Tese (Doutorado em Educação) - Programa de Pós-Graduação em Educação, Universidade Federal do Rio Grande do Sul, Porto Alegre, 2008.

Fabiane Romano de Souza Bridi é doutora em Educação pela Universidade Federal do Rio Grande do Sul (UFRGS). Integrante do Núcleo de Estudos e Políticas de Inclusão Escolar - NEPIE/UFRGS. Professora Adjunta do Departamento de Educação Especial da Universidade Federal de Santa Maria (UFSM). E-mail: fabianebridi@gmail.com

Melina Chassot Benincasa Meirelles é doutoranda em Educação no Programa de Pós-Graduação da Universidade Federal do Rio Grande do Sul (PPGEDU/UFRGS). Bolsista CAPES/PROESP. Integrante do Núcleo de Estudos e Políticas de Inclusão Escolar - NEPIE/UFRGS.

E-mail: melinabenincasa@gmail.com 